Research Article

\title{
Flexural Fatigue Behaviors of Silicon Carbide Recycled Concrete in Corrosive Environments
}

\author{
Jinzhi Zhou $\mathbb{D}^{1},{ }^{1}$ Tiantian Fu $\mathbb{D}^{1},{ }^{1}$ Chuheng Zhong $\mathbb{D}^{1}{ }^{1}$ Kun Peng, ${ }^{2}$ and Ziyang Shuang ${ }^{3}$ \\ ${ }^{1}$ College of Civil Engineering Architecture and Environment, Hubei University of Technology, Wuhan 430068, China \\ ${ }^{2}$ The Third Construction Co., Ltd. of China Construction Third Engineering Bureau, Wuhan 430068, China \\ ${ }^{3}$ The First Company of China Eighth Engineering Bureau Ltd., Guangzhou 510700, China \\ Correspondence should be addressed to Chuheng Zhong; chuheng.zhong@hbut.edu.cn
}

Received 11 April 2021; Accepted 29 June 2021; Published 9 July 2021

Academic Editor: Rihong Cao

Copyright ( $\odot 2021$ Jinzhi Zhou et al. This is an open access article distributed under the Creative Commons Attribution License, which permits unrestricted use, distribution, and reproduction in any medium, provided the original work is properly cited.

\begin{abstract}
An experimental study on the flexural fatigue behaviors of recycled concrete (RC) and silicon carbide recycled concrete (SiCRC) was conducted. The immersion time was $0 \mathrm{~d}, 30 \mathrm{~d}, 60 \mathrm{~d}$, and $90 \mathrm{~d}$ in $5 \% \mathrm{NaCl}$ solution for these two kinds of recycled concrete specimens, respectively, and then, four-point flexural fatigue tests were performed by MTS fatigue testing machine. The fatigue life for varying stress levels ranging from 0.9 to 0.6 was obtained. The fatigue life was given considering the failure probability according to the fatigue life and stress level of the specimen via the logarithmic normal distribution and Weibull distribution, respectively. The relationship between fatigue life and failure probability was also obtained. The fatigue life with failure probability of $1 \%$ and $50 \%$ was further predicted. The results showed that the fatigue life of RC and SiCRC increased in corrosive environments. The fatigue life of SiCRC is higher than that of RC, and the incorporation of SiCRC can improve the fatigue life of recycled concrete.
\end{abstract}

\section{Introduction}

With the development of the city, construction waste is growing. It is conservatively estimated that, over the next 10 years, China will produce more than 1.5 billion tons of construction waste per year, reaching 7.3 billion tons in 2030 [1]. At present, the construction waste are mainly brick and concrete, which are treated as recycled aggregate and prepared as inorganic mixture for road pavement base. Considering environment and economy, replacing nonrenewable natural aggregate with renewable construction waste, construction waste recycling can not only reduce carbon emissions but also lower costs $[2,3]$.

Many scholars at home and abroad have studied the mechanics and durability of recycled concrete [4-10]. Ramesh et al. [11] found that the split-tensile strength, the compressive strength, and the elastic modulus of recycled concrete with substitution rate of $30 \%, 50 \%, 70 \%$, and $100 \%$ were lower than that of natural concrete, and the splitting tensile strength can be increased by $0.7 \%$ after incorporation of steel fiber. Aref et al. [12] showed that it was feasible to build self-compacting concrete with a $100 \%$ replacement rate of recycled aggregate. Rahal [13] found that the compressive strength and indirect shear strength of 28-day cube and cylinder of recycled aggregate concrete were $90 \%$ of natural aggregate concrete under the same mix proportions. Thomas et al. [14] discussed the effect of recycled aggregate on concrete under the same $w / c$ ratio by partially and completely replacing natural aggregate. The durability of recycled aggregate concrete was poor due to the porosity of recycled aggregate itself. Subsequently, Pinghua Zhu et al. [15] reported the durability of recycled concrete with different substitution rates under the coupling of freeze-thaw cycle and chloride erosion.

However, many engineering structures such as bridge decks, piers, offshore structures, highway pavements, and railway sleepers are more vulnerable to fatigue loading [16]. Therefore, scholars have also carried out studies on the fatigue properties of recycled concrete. Singh and Kaushik [17] found that steel fiber recycled concrete statistical 
distribution of equivalent fatigue life at a given stress level S, approximately, submitted to the two-parameter Weibull distribution. Cusson et al. [18] mentioned that because of the increase of traffic load and the change of environmental conditions, deterioration will affect the service life of the bridge; the use of deicing salt on the road in winter will lead to more serious corrosion deterioration and reduce its durability. The test under the coupled action of freezingthawing cycles and chloride attack was completed by Hao et al. [19] The results showed that the bending stress had significant negative effect on the frost resistance of RATIC. Wang et al. [20] found that silicon carbide concrete had better working performance on compressive and flexural strength than that of ordinary concrete. Silicon carbide can be used as wear-resistant floor in logistics workshop and distribution workshop to enhance the wear resistance of pavement [21].

In conclusion, the flexural fatigue performance of common recycled concrete and silicon carbide recycled concrete in corrosion environment will be studied by experiments in this paper in order to obtain useful conclusions.

\section{Experimental Program}

2.1. Materials. In this experiment, constituents of silicon carbide recycled concrete (SiCRC) are Ordinary Portland Cement, coarse aggregates, river sand, manufactured sand, silicon carbide, and admixtures. Ordinary Portland Cement has been obtained from the local supplier. Coarse aggregates have NA and RA two types. Particle size of NA and RA of is 5-30 mm, whose physical properties are given in Table 1 . The RA used in this study was completely wetted by spraying water. Fine aggregate was river sand and silicon carbide. The fineness modulus of river sand is 2.8 , which belongs to medium sand in II area, with mud content of $0.7 \%$. The size of silicon carbide is $1190 \mu \mathrm{m}$. Admixtures are polycarboxylic acid. The water-reduction rate of that is $30 \%$, and the gas and solid content is about $4.7 \%$ and $8.8 \%$. Fly ash and slag as materials were mingled to improve the performance of specimens. Chloride containing environment is $5 \% \mathrm{NaCl}$ solution.

2.2. Specimen. The experiment carries on the mix proportion design of the reference concrete C30 according to the JCJ55-2011 (Specification for Mix Proportion Design of Ordinary Concrete). The substitution rate of recycled aggregate is $20 \%$ in RC. Further, based on RC, $10 \%$ fine aggregate can be replaced with an equal volume of silicon carbide, which made SiCRC.

There are two kinds of concrete specimens, the mineral powder is $100 \mathrm{~kg} / \mathrm{m}^{3}$, the cement is $210 \mathrm{~kg} / \mathrm{m}^{3}$, the fly ash is $60 \mathrm{~kg} / \mathrm{m}^{3}$, and the water and water reducer are $160 \mathrm{~kg} / \mathrm{m}^{3}$ and $7.4 \mathrm{~kg} / \mathrm{m}^{3}$, respectively. The amount of other materials is given in Table 2 . The flexural fatigue test was carried out with $150 \mathrm{~mm} \times 150 \mathrm{~mm} \times 550 \mathrm{~mm}$ standard trabecular specimens. It has 2 mix proportion and 8 groups of specimens. The flexural fatigue specimens of each group were 9 . The specimens were standard cured for $28 \mathrm{~d}$. Then, specimens' soaking time periods were $0,30,60$, and $90 \mathrm{~d}$ in $5 \% \mathrm{NaCl}$ solution.

\section{Test Methods}

Fatigue test was carried out on the MTS in the structure hall of Hubei University of Technology, as shown in Figure 1. Loading mode selected load control, four-point bending method, and sine wave cycle loading mode; loading frequency is $10 \mathrm{~Hz}$; the stress level is $0.6,0.7$, and 0.9 ; the test flow is shown in Figure 2.

\section{Test Results and Analysis}

4.1. Experimental Phenomena. The results show that white spots and concave-convex pits are produced on the surface of RC and SiCRC specimens after chlorine salt soaking. With loading, crack gradually appears in the middle of the tension side of the specimen and extends to the compression zone. Due to the weak bond between coarse aggregate and cement gel, when loaded to the ultimate load, the specimen produced brittle fractures, accompanied by the sound of bang. The destroyed image is shown in Figure 3.

4.2. Fatigue Test Data. The results of the fatigue tests as obtained in this investigation are given in Tables 3 and 4 . In bending fatigue tests, even with the same batch of raw materials, the produced samples are differences. Because silicon carbide recycled concrete is a composite, it has been treated with chlorine salt soaking. Fatigue failure is more complicated than static load failure. The results of fatigue test are very discrete. $S-N$ relation graph is a widely accepted method to evaluate the fatigue life of practical engineering. When considering the effect of minimum stress, constant life fatigue diagram can be used such as Haigh or Smith diagrams to represent. The recycled concrete has a different fatigue life under different bending fatigue stress levels. The relationship between stress level $S$ and fatigue life $N$ can be described by the rectangular Cartesian coordinate system. The $S$ - $N$ curve can clearly and intuitively describe the fatigue characteristics of materials [4]. Figure 4 shows the $S-N$ curves of recycled concrete of different types and different immersion ages showing the relationship between fatigue life $(N)$ and stress level $(S)$, respectively.

It can be seen from Figure 4 that the fatigue life of each group of recycled concrete specimens decreases with the increase of stress level. When the stress level is certain, with the increase of soaking age, the fatigue life of recycled concrete and silicon carbide recycled concrete increases. When the stress level is certain and the soaking age is the same, the fatigue life of silicon carbide recycled concrete under chlorine salt immersion is higher than that of recycled concrete.

Without the chlorine, due to the higher porosity and lower strength of RC, the size of silicon carbide is small and can be filled between other aggregate gaps, which improves the density of concrete. The addition of silicon carbide and coal fly ash improves the inner capillary structure of concrete and improves the bonding ability of concrete as a whole. Meanwhile, the hydroxyl of concrete admixture and silicon carbide, main components' $\mathrm{SiC}$ on the surface, and oxygen 
TABle 1: Physical properties of coarse aggregate.

\begin{tabular}{lcccc}
\hline Category & Particle size $(\mathrm{mm})$ & Water absorption $(\%)$ & Apparent density $\left(\mathrm{kg} / \mathrm{m}^{3}\right)$ & Crushing value $(\%)$ \\
\hline Recycled coarse aggregate & $5 \sim 30$ & 9.5 & 2520 & 14.9 \\
Natural coarse aggregate & $5 \sim 30$ & 0.9 & 2650 & 9 \\
\hline
\end{tabular}

TABle 2: Mixture proportion $\left(\mathrm{kg} / \mathrm{m}^{3}\right)$.

\begin{tabular}{lccccccc}
\hline Concrete type & Cement & NA & RA & Silicon carbide & Manufactured sand & River sand & Water \\
\hline RC & 210 & 824 & 206 & - & 380 & 455 \\
SiCRC & 210 & 824 & 206 & 83.5 & 342 & 160 \\
\hline
\end{tabular}

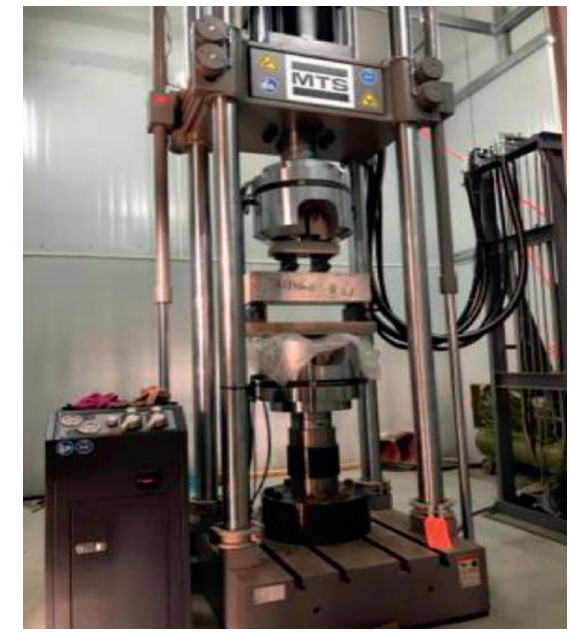

(a)

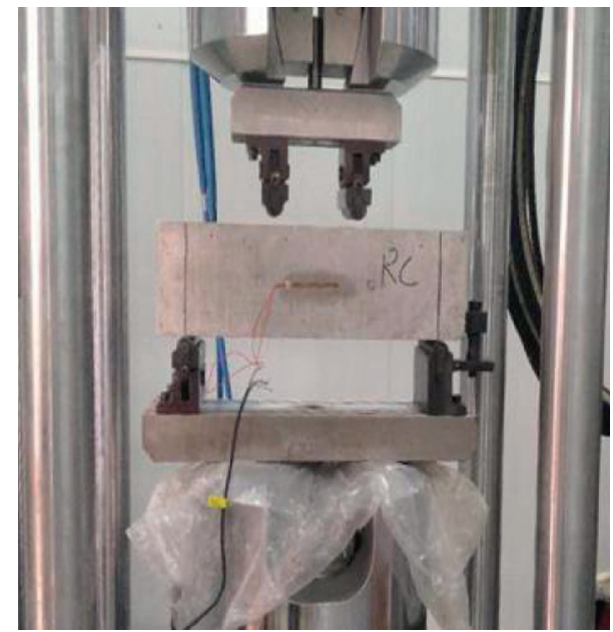

(b)

Figure 1: Fatigue test equipment.

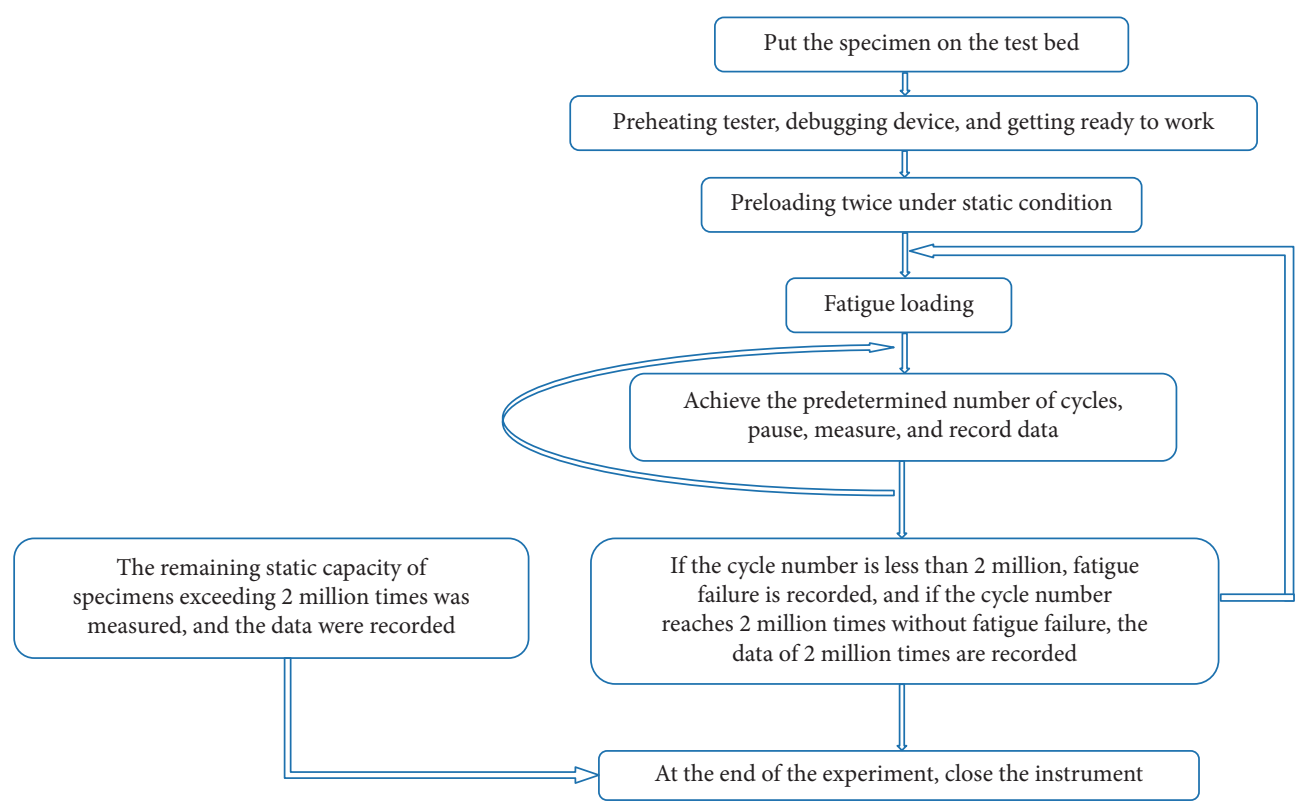

Figure 2: Test procedure for fatigue test. 


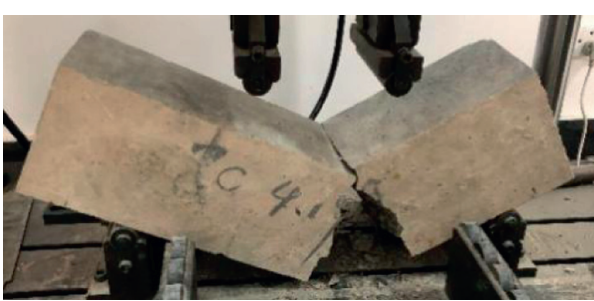

(a)

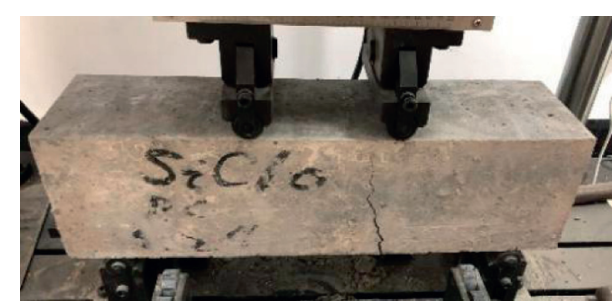

(b)

Figure 3: Failure morphology of specimens.

TABLE 3: Fatigue life $(N)$ for RC.

\begin{tabular}{lcccc}
\hline Specimen no. & \multicolumn{2}{c}{ Stress level } & \multicolumn{2}{c}{ Fatigue life data $(N)$} \\
\hline & 0.9 & 113 & 211 & 319 \\
RC $(0 \mathrm{~d})$ & 0.7 & 14647 & 31841 & 45239 \\
& 0.6 & 57981 & 106042 & 148596 \\
\hline \multirow{3}{*}{ RC (30 d) } & 0.9 & 125 & 223 & 332 \\
& 0.7 & 16135 & 33855 & 48271 \\
& 0.6 & 60458 & 108267 & 151029 \\
\hline \multirow{2}{*}{ RC $(60 \mathrm{~d})$} & 0.9 & 136 & 236 & 346 \\
& 0.7 & 17737 & 35324 & 50736 \\
& 0.6 & 62549 & 110749 & 153773 \\
\hline \multirow{3}{*}{ RC (90 d) } & 0.9 & 145 & 247 & 357 \\
& 0.7 & 19319 & 36973 & 52632 \\
& 0.6 & 64597 & 112823 & 156175 \\
\hline
\end{tabular}

TABle 4: Fatigue life $(N)$ for SiCRC.

\begin{tabular}{lcccc}
\hline Specimen no. & \multicolumn{2}{c}{ Stress level } & \multicolumn{2}{c}{ Fatigue life data $(N)$} \\
\hline \multirow{3}{*}{ SiCRC $(0 \mathrm{~d})$} & 0.9 & 255 & 404 & 612 \\
& 0.7 & 22716 & 61953 & 93326 \\
& 0.6 & 70463 & 135524 & 196022 \\
\hline \multirow{3}{*}{ SiCRC (30 d) } & 0.9 & 262 & 408 & 619 \\
& 0.7 & 23941 & 63117 & 94565 \\
& 0.6 & 71926 & 137033 & 197576 \\
\hline \multirow{3}{*}{ SiCRC (60 d) } & 0.9 & 266 & 413 & 623 \\
& 0.7 & 24851 & 64028 & 95447 \\
& 0.6 & 73942 & 139031 & 199527 \\
\hline \multirow{3}{*}{ SiCRC (90 d) } & 0.9 & 272 & 419 & 631 \\
& 0.7 & 26044 & 65238 & 96646 \\
& 0.6 & 76186 & 141231 & 201767 \\
\hline
\end{tabular}

atom with strong negative charge in cement clinker molecules generate a hydrogen bond, which further improves the strength of concrete.

After soaking in chloride, the fatigue life of SiCRC increases as follows. In the long-term immersion of $\mathrm{NaCL}$ solution, chlorine salt diffuses into the concrete with the increase of soaking age. Because a large number of chloride ions exist, the crystals of salt are formed in concrete. It is mainly that tricalcium aluminate combines with chloride ion to form "Fessler salt." At the same time, the cement hydration will continue to produce calcium hydroxide and other substances, which will make the interior of concrete more dense. The connection between

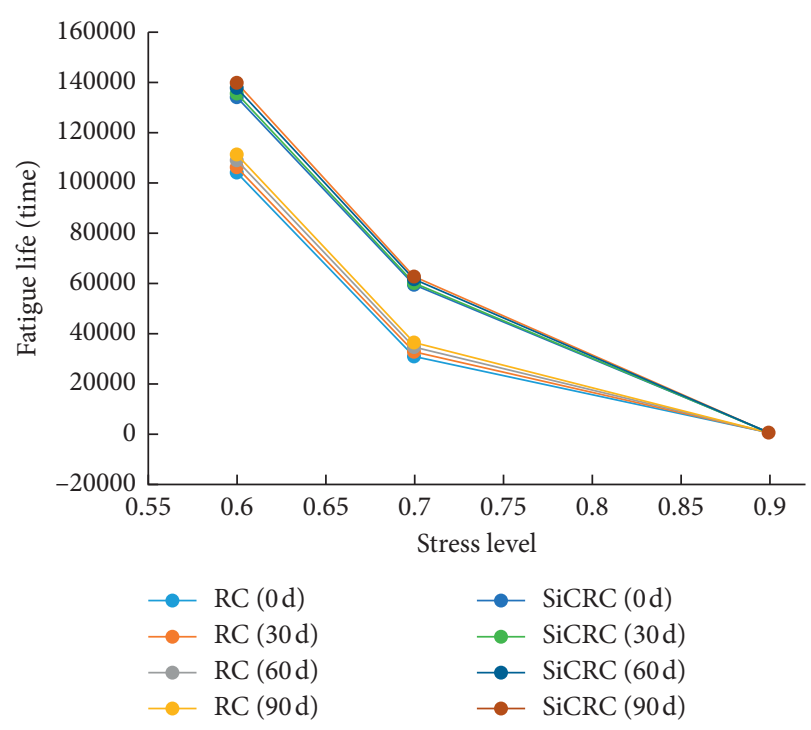

Figure 4: $S$ - $N$ curves.

the aggregate inside the concrete closer and strength of the concrete increases. Silicon carbide is a kind of aggregate with high toughness and hardness, and the SiCRC is a kind of material with good uniformity. The addition of silicon improves toughness and crack resistance of concrete as a whole. The performance of RC under the condition of chlorine salt soaking and the mechanism of chlorine salt erosion are similar to $\mathrm{SiCRC}$, but the fatigue life performance is not as good as that of SiCRC because of the lack of the addition of silicon improves.

\section{Numerical Distribution Analysis}

On the strength and fatigue life of concrete materials, scholars mostly use the lognormal distribution model and the Weibull distribution model [22-25]. In this section, lognormal distribution and two-parameter Weibull distribution model will be used to analyze the fatigue performance of recycled concrete in chloride immersion.

5.1. Lognormal Distribution. The logarithm of specimens' fatigue life $(S=\operatorname{lgN})$ obeys normal distribution; then, the probability density function is as follows: 


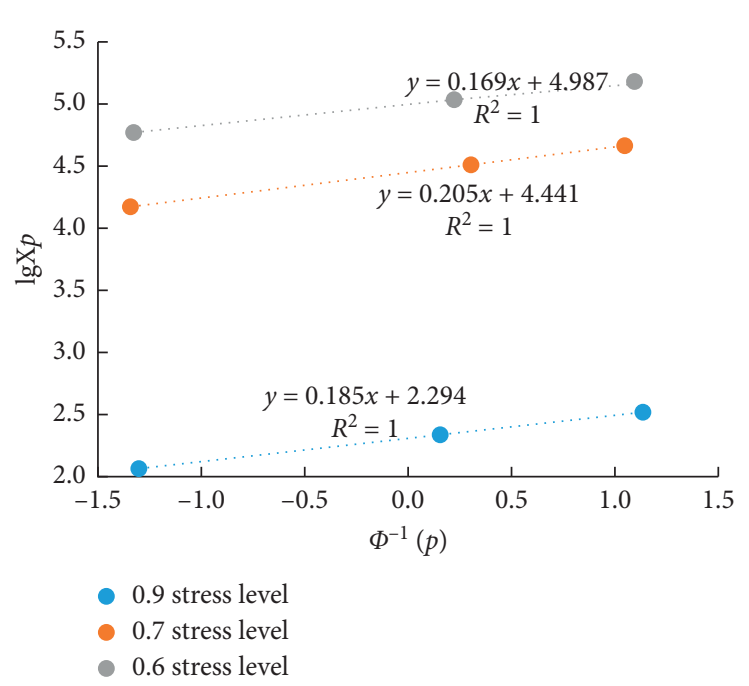

(a)

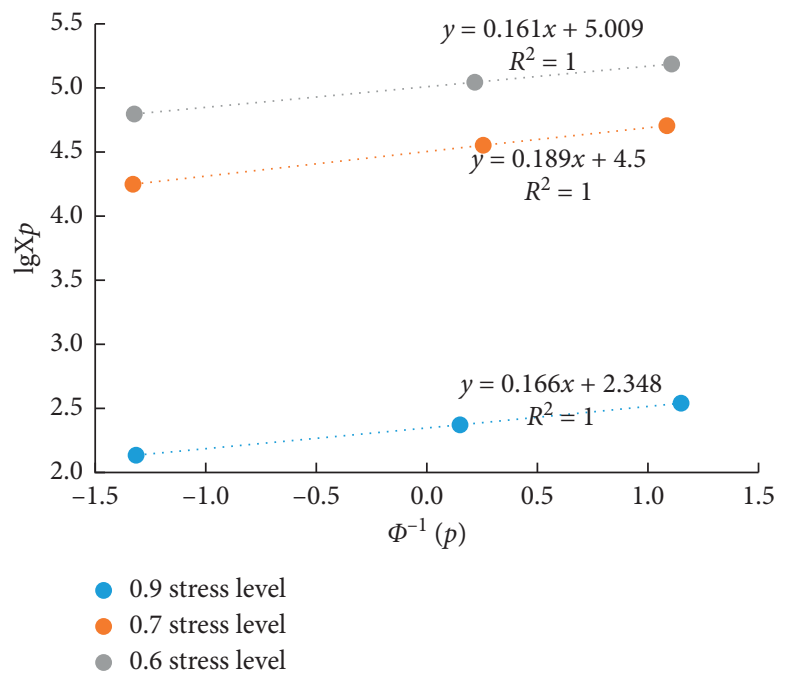

(c)

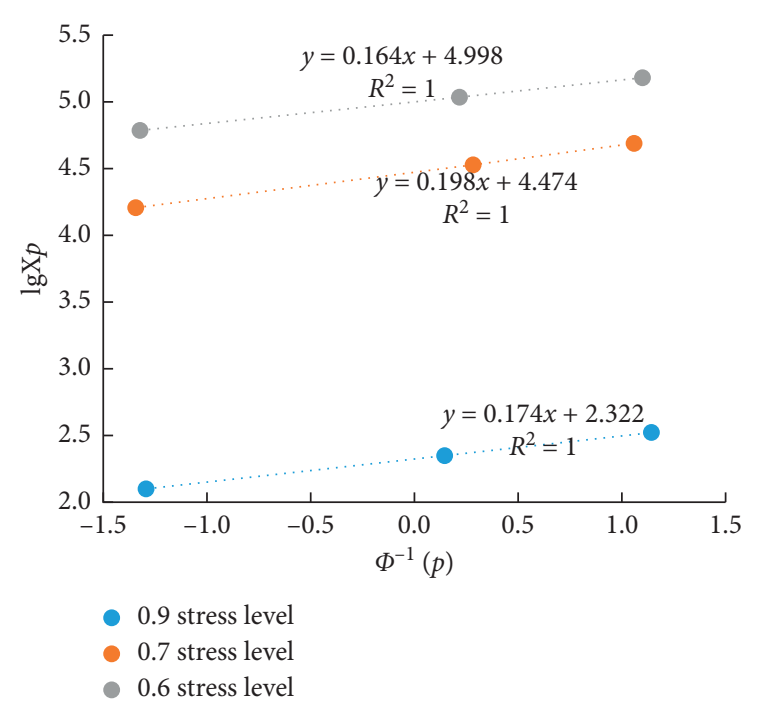

(b)

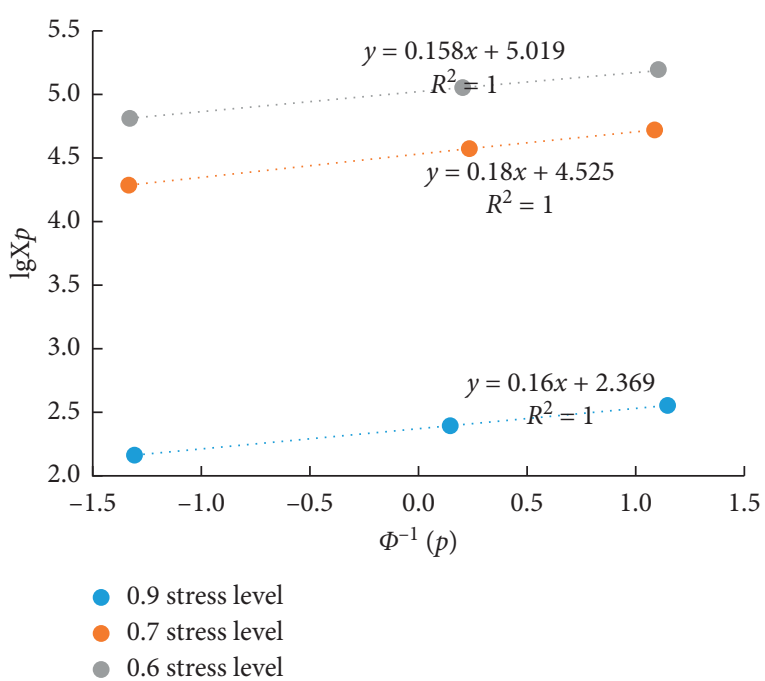

(d)

Figure 5: RC linear regression. (a) RC (0 d). (b) RC (30 d). (c) RC (60 d). (d) RC (90 d).

$$
f_{N}(n)=\frac{1}{\sqrt{2 \pi} \ln 10 \sigma_{0} n} \exp \left[-\frac{\left(\lg n-\mu_{0}\right)^{2}}{2 \sigma_{0}^{2}}\right] \text {, }
$$

where $\mu_{0}$ and $\sigma_{0}$ of $\lg N$ are average value and standard deviation and distribution parameters $N$ is the random variable:

$$
F_{N}(n)=P(N \leq n)=\varphi\left(\frac{\lg n-\mu_{0}}{\sigma_{0}}\right) .
$$

The function values to the cumulative distribution function is called cumulative failure probability or unreliable. Then, the reliability function is as follows:

$$
R_{N}(n)=1-F_{X}(x)=1-\varphi\left(\frac{\lg n-\mu_{0}}{\sigma_{0}}\right) .
$$

In order to regress the model distribution parameters, the cumulative failure probability is known to be $p$. Taking $\varphi^{-1}(\cdot)$ on both sides at the same time, reliability life of $(1-p)$ is as follows:

$$
\lg n_{p}=\mu_{0}+\varphi^{-1}(p) \sigma_{0}
$$

When $Y=\lg x_{p}, Z=\varphi^{-1}(p), a=\mu_{0}$, and $b=\sigma_{0}$, equation (4) can be transformed into the following primary linear equation:

$$
\begin{aligned}
Y & =a+b N, \\
\widehat{\mu}_{0} & =\widehat{a}, \\
\widehat{\sigma}_{0} & =\widehat{b} .
\end{aligned}
$$




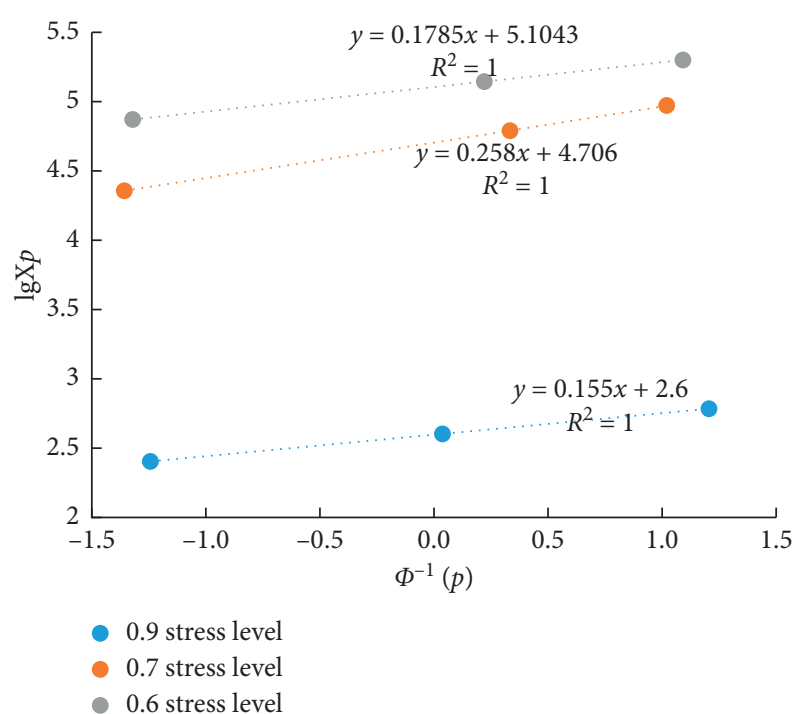

(a)

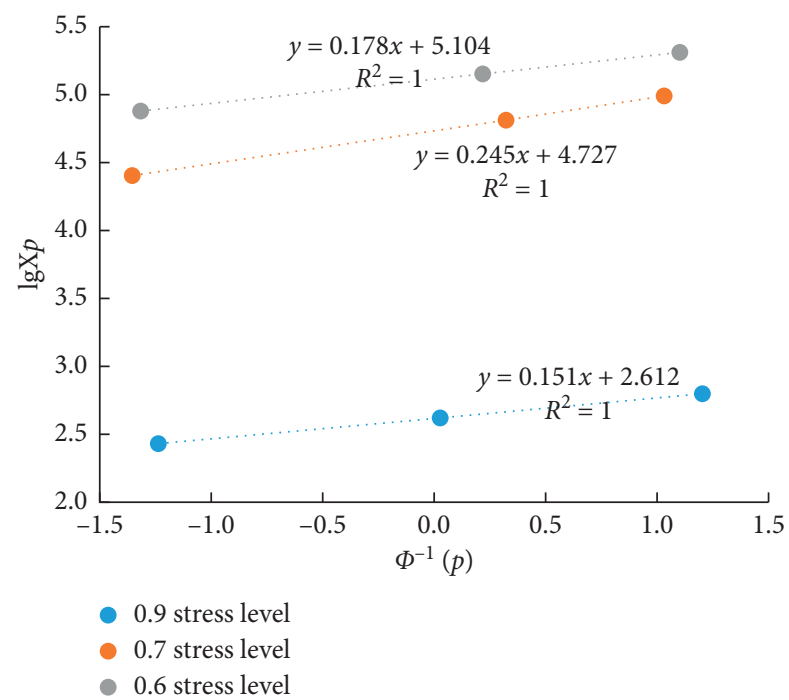

(c)

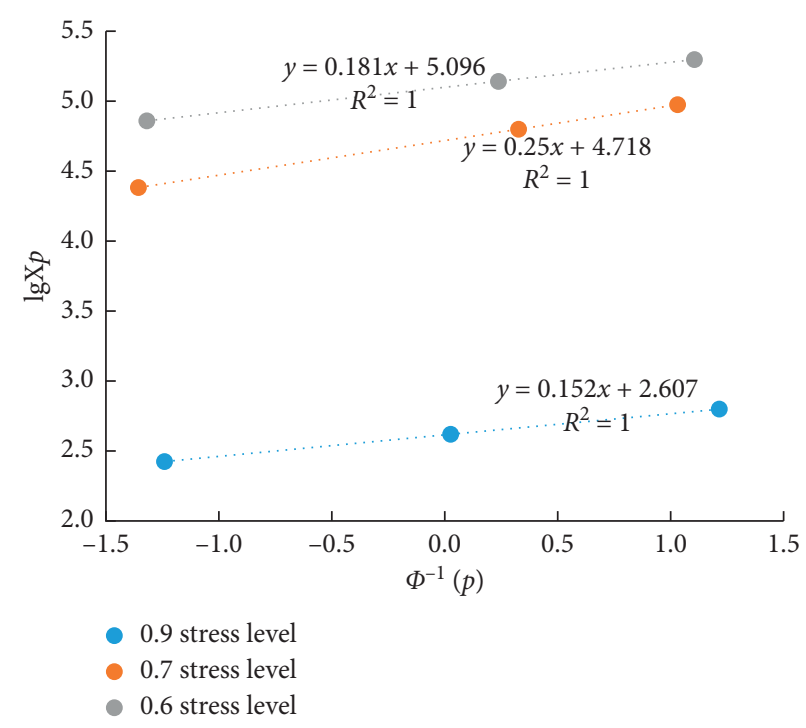

(b)

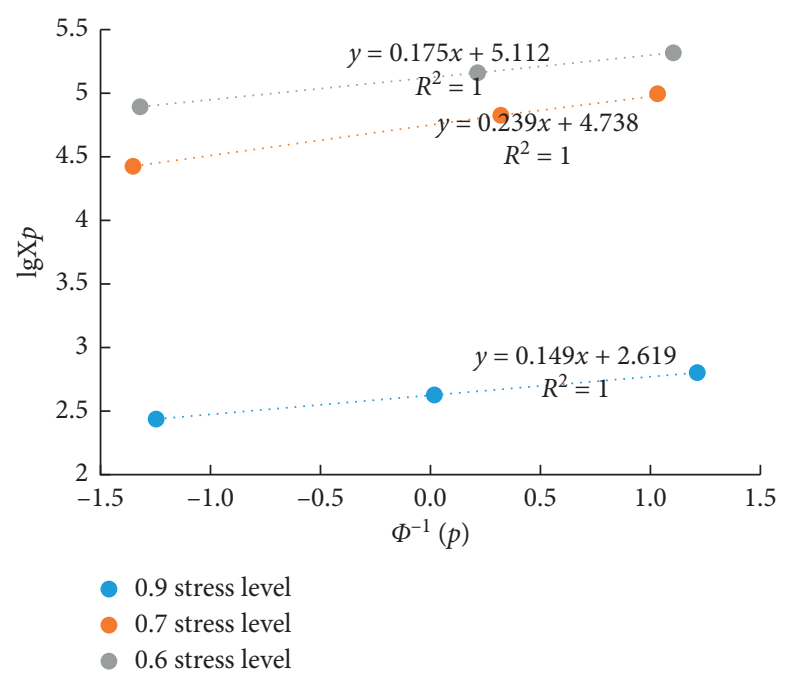

(d)

Figure 6: SiCRC linear regression. (a) SiCRC (0 d). (b) SiCRC (30 d). (c) SiCRC (60 d). (d) SiCRC (90 d).

$a$ and $b$ can be obtained by regression of test data with formula (5) to determine the distribution parameters $\mu_{0}$ and $\sigma_{0}$.

Fatigue life of RC and SiCRC in corrosive environments was analyzed by using lognormal distribution theory. The fitting results are shown in Figures 5 and 6.

5.2. Weibull Distribution. According to Weibull distribution theory, the distribution law of fatigue life $N$ of each specimen can be expressed by Weibull function under the same stress level:

$$
Y=b X-a,
$$

where $Y=\ln [\ln (1 / p)], X=\ln N$, and $a=b \ln N_{a}$.

The data of fatigue life are brought into $Y$ and $X$, and the data are regressed analysis. The data show a clear linear relationship; then, the results show that the data of four- point bending fatigue test accord with the two-parameter Weibull distribution. On the contrary, the assumption is not tenable.

Fatigue life of RC and SiCRC in corrosive environments was analyzed by using Weibull distribution theory. The fitting results are shown in Figures 7 and 8.

From Figures 5-8 and Table 5, all the correlation coefficient $R^{2}$ is 1.0 by using lognormal distribution and $R^{2}$ is above 0.95 by using Weibull distribution. The results show that the fatigue life of the two kinds of concrete under the condition of chlorine salt soaking is better from lognormal distribution and Weibull distribution at different ages. Both the lognormal distribution and the two-parameter Weibull distribution, the fatigue life of chloride attack increased to varying degrees compared with that before chloride attack.

For the normal distribution theory, the correlation coefficient $R^{2}$ is 1.0 , which indicates that it is completely 


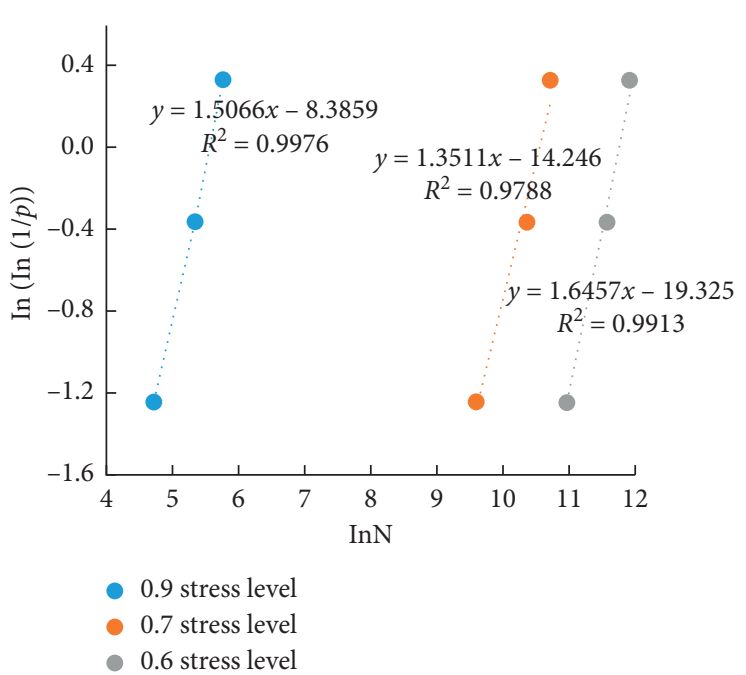

(a)

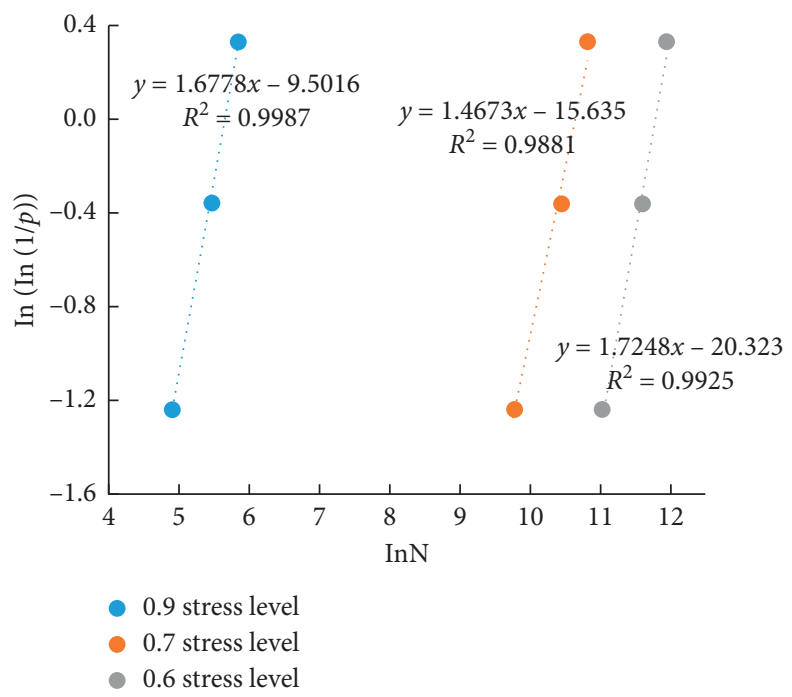

(c)

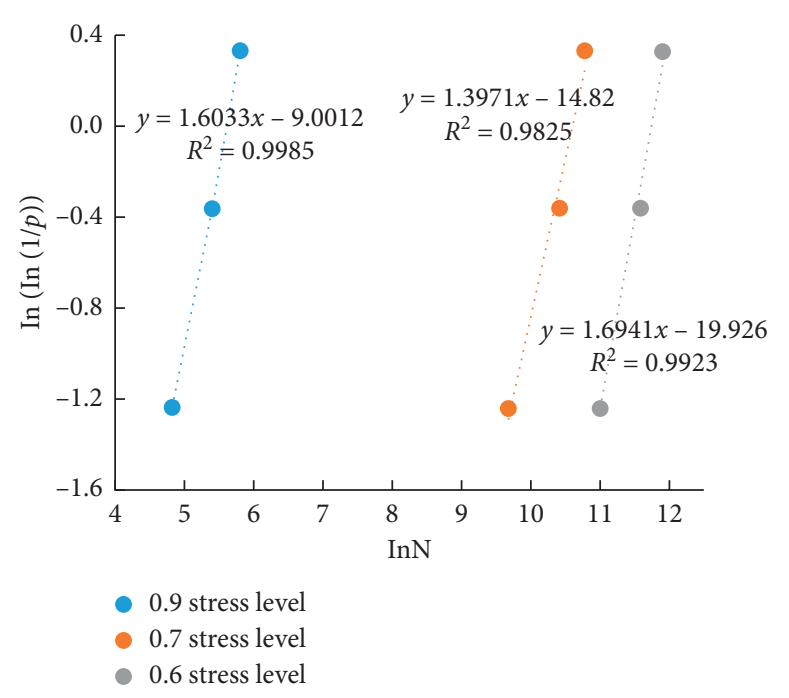

(b)

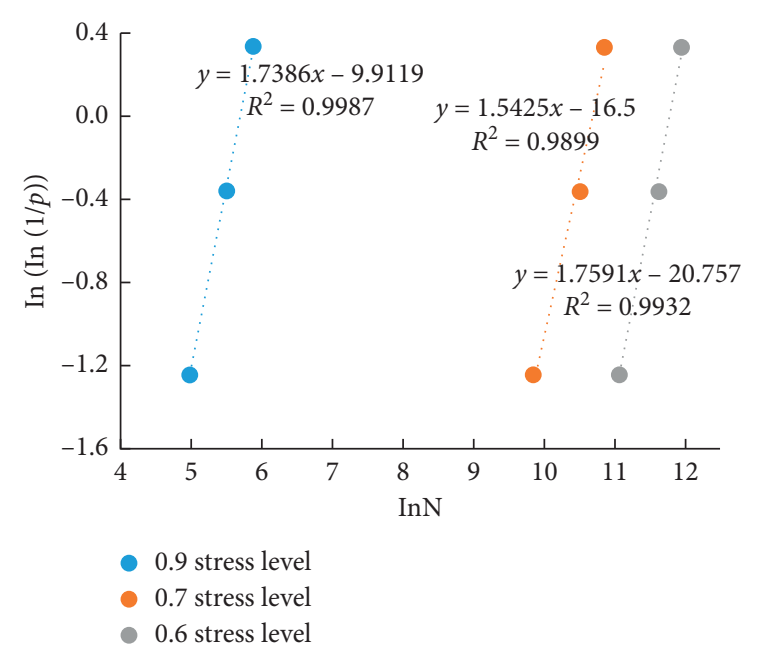

(d)

Figure 7: RC linear regression. (a) RC (0d). (b) RC (30 d). (c) RC (60 d). (d) RC (90 d).

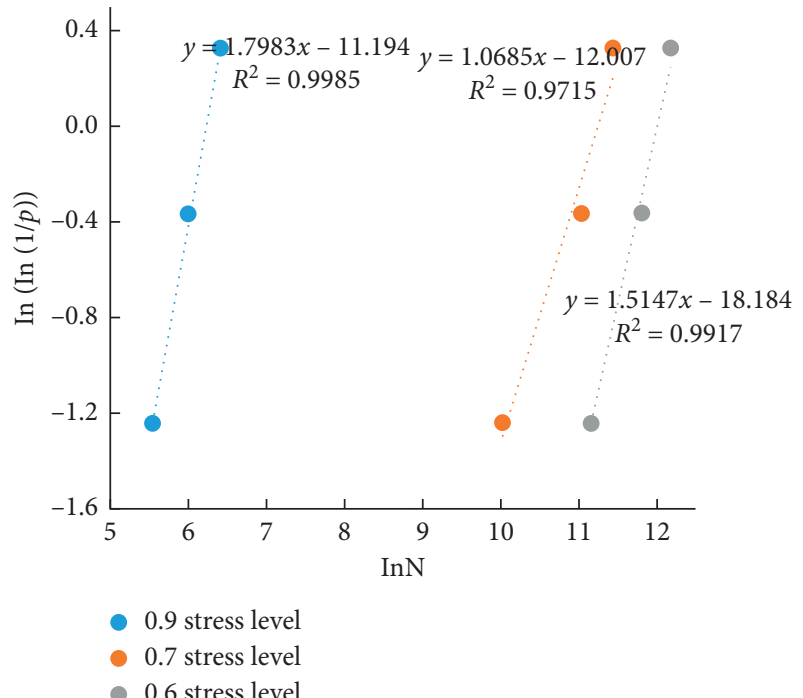

(a)

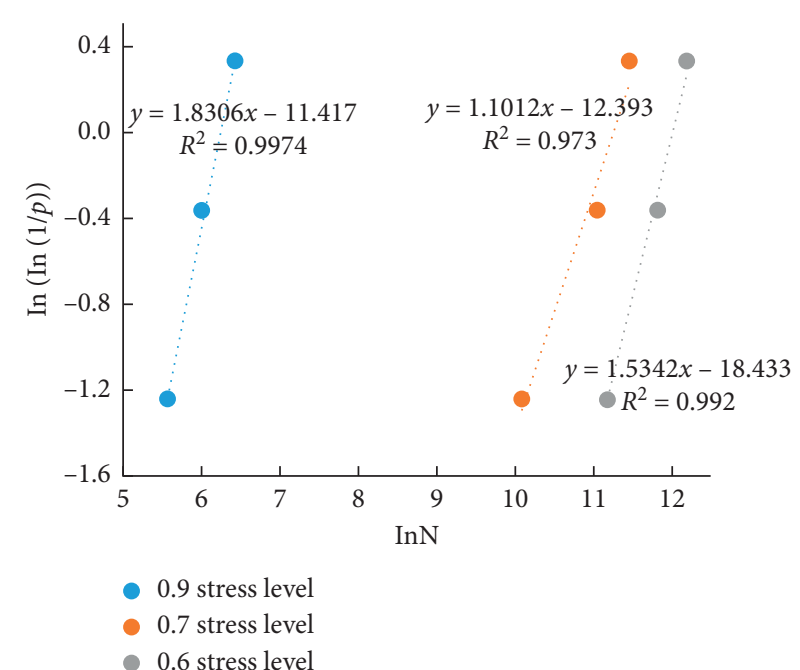

(b)

FIGURE 8: Continued. 


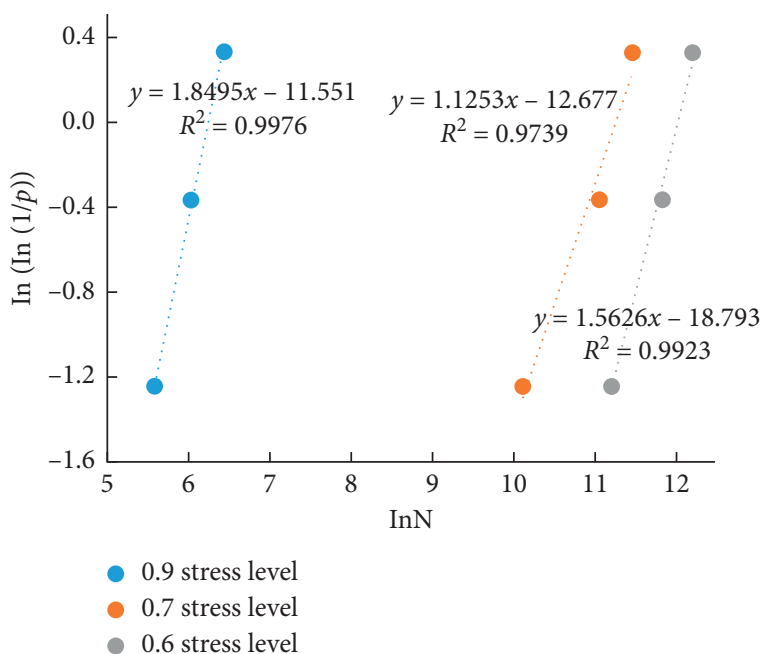

(c)

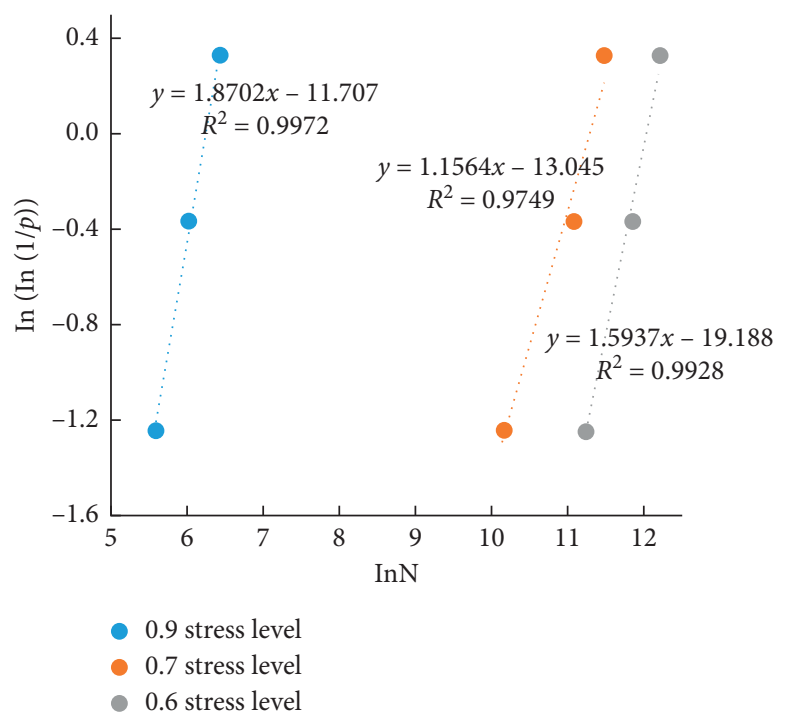

(d)

FIgURe 8: SiCRC linear regression. (a) SiCRC (0d). (b) SiCRC (30 d). (c) SiCRC (60 d). (d) SiCRC (90 d).

TABLE 5: Fitting results of lognormal distribution and Weibull distribution.

\begin{tabular}{|c|c|c|c|c|c|c|c|c|c|c|c|}
\hline \multirow{3}{*}{ Group number } & \multirow{3}{*}{ Max stress level } & \multicolumn{5}{|c|}{ Lognormal distribution } & \multicolumn{5}{|c|}{ Weibull distribution } \\
\hline & & \multirow[t]{2}{*}{$a$} & \multirow[t]{2}{*}{$b$} & \multirow[t]{2}{*}{$R^{2}$} & \multicolumn{2}{|c|}{$\begin{array}{c}\text { Failure } \\
\text { probability }\end{array}$} & \multirow[t]{2}{*}{$a$} & \multirow[t]{2}{*}{$b$} & \multirow[t]{2}{*}{$R^{2}$} & \multicolumn{2}{|c|}{$\begin{array}{c}\text { Failure } \\
\text { probability }\end{array}$} \\
\hline & & & & & $1 \%$ & $50 \%$ & & & & $1 \%$ & $50 \%$ \\
\hline \multirow{3}{*}{$\mathrm{RC}(0 \mathrm{~d})$} & 0.9 & 2.294 & 0.185 & 1.0 & 73 & 197 & 1.5066 & 8.3859 & 0.9976 & 59 & 205 \\
\hline & 0.7 & 4.41 & 0.205 & 1.0 & 8572 & 25704 & 1.3511 & 14.246 & 0.9788 & 7175 & 28933 \\
\hline & 0.6 & 4.987 & 0.169 & 1.0 & 39250 & 97051 & 1.6457 & 19.325 & 0.9913 & 32058 & 100711 \\
\hline \multirow{3}{*}{$\mathrm{RC}(30 \mathrm{~d})$} & 0.9 & $R^{2}$ & 0.174 & 1.0 & 83 & 210 & 1.6033 & 9.001 & 0.9985 & 67 & 218 \\
\hline & 0.7 & 4.474 & 0.198 & 1.0 & 10312 & 29785 & 1.3971 & 14.82 & 0.9825 & 8078 & 31112 \\
\hline & 0.6 & 4.998 & 0.164 & 1.0 & 41350 & 99541 & 1.6941 & 19.926 & 0.9923 & 33984 & 103327 \\
\hline \multirow{3}{*}{$\mathrm{RC}(60 \mathrm{~d})$} & 0.9 & 2.348 & 0.166 & 1.0 & 92 & 223 & 1.6778 & 9.502 & 0.9987 & 75 & 232 \\
\hline & 0.7 & 4.5 & 0.189 & 1.0 & 11490 & 31623 & 1.4673 & 15.635 & 0.9881 & 9154 & 33052 \\
\hline & 0.6 & 5.009 & 0.161 & 1.0 & 43098 & 102094 & 1.7248 & 20.323 & 0.9925 & 35529 & 105907 \\
\hline \multirow{3}{*}{$\mathrm{RC}(90 \mathrm{~d})$} & 0.9 & 2.369 & 0.16 & 1.0 & 99 & 234 & 1.7386 & 9.9119 & 0.9987 & 82 & 242 \\
\hline & 0.7 & 4.525 & 0.18 & 1.0 & 12771 & 33497 & 1.5425 & 16.5 & 0.9899 & 10281 & 34868 \\
\hline & 0.6 & 5.019 & 0.158 & 1.0 & 44816 & 104472 & 1.7591 & 20.757 & 0.9932 & 37068 & 108167 \\
\hline \multirow{3}{*}{ SiCRC $(0 \mathrm{~d})$} & 0.9 & 2.6 & 0.155 & 1.0 & 173 & 398 & 1.7983 & 11.194 & 0.9985 & 145 & 412 \\
\hline & 0.7 & 4.706 & 0.258 & 1.0 & 12758 & 50816 & 1.0685 & 12.007 & 0.9715 & 9239 & 53865 \\
\hline & 0.6 & 5.104 & 0.178 & 1.0 & 48875 & 127151 & 1.5147 & 18.184 & 0.9917 & 37024 & 128418 \\
\hline \multirow{3}{*}{ SiCRC (30 d) } & 0.9 & 2.607 & 0.152 & 1.0 & 179 & 405 & 1.8306 & 11.417 & 0.9974 & 149 & 418 \\
\hline & 0.7 & 4.718 & 0.25 & 1.0 & 13690 & 52240 & 1.1012 & 12.393 & 0.9731 & 10002 & 55340 \\
\hline & 0.6 & 5.096 & 0.181 & 1.0 & 47308 & 124738 & 1.5342 & 18.433 & 0.992 & 38072 & 129971 \\
\hline \multirow{3}{*}{ SiCRC $(60 d)$} & 0.9 & 2.612 & 0.151 & 1.0 & 182 & 409 & 1.8496 & 11.551 & 0.9976 & 153 & 423 \\
\hline & 0.7 & 4.727 & 0.245 & 1.0 & 13456 & 53333 & 1.1253 & 12.677 & 0.9739 & 10569 & 56373 \\
\hline & 0.6 & 5.104 & 0.178 & 1.0 & 48968 & 127057 & 1.5626 & 18.793 & 0.9923 & 39601 & 132217 \\
\hline \multirow{3}{*}{ SiCRC (90 d) } & 0.9 & 2.619 & 0.149 & 1.0 & 187 & 416 & 1.8702 & 11.707 & 0.9972 & 157 & 430 \\
\hline & 0.7 & 4.738 & 0.239 & 1.0 & 15206 & 54702 & 1.1564 & 13.045 & 0.9749 & 11324 & 57743 \\
\hline & 0.6 & 5.112 & 0.175 & 1.0 & 50686 & 129420 & 1.5937 & 19.188 & 0.9928 & 41269 & 134582 \\
\hline
\end{tabular}

correlated. It does not match the actual situation, and there is a little error.

For the Weibull distribution theory, when the stress level is the same, the correlation coefficient $R^{2}$ increases gradually with the increase of soaking age, which shows that the linear relationship is enhanced. When the soaking age is the same, the correlation coefficient of the same type concrete is higher at the stress level 0.9. When the stress level and soaking age 
are the same, the SiCRC's correlation coefficient $R^{2}$ is higher than RC, which indicates that the straight line fitting effect is better. In addition, at the high stress level, the fitting discreteness of fatigue life is large, the fatigue life is 0 when the failure probability is 0 , which is wrong with the actual existence.

\section{Conclusions}

(1) The fatigue life of each concrete specimens decreases with the increase of the stress level, and the fatigue life of both types of concrete increases with the increase of soaking age when the stress level is fixed.

(2) The fatigue life of RC and SiCRC increased in corrosive environments. The fatigue life of SiCRC is higher than that of RC, and the incorporation of SiCRC can improve the fatigue life of recycled concrete.

(3) By both the lognormal distribution and two-parameter Weibull distribution, the fatigue life for chlorine salt erosion increased in varying degrees under the corresponding failure probability.

\section{Data Availability}

The data used to support the findings of this study are included within the article.

\section{Conflicts of Interest}

The authors declare no conflicts of Interest.

\section{Acknowledgments}

This research was financially supported by the State Key Laboratory for Health and Safety of Bridge Structures (Grant no. BHSKL19-04-KF) and Teaching Research Project of Higher Educational Institutions of Hubei Province (2017314). The authors would like to express their appreciation to these financial assistances.

\section{References}

[1] "Rule of law daily," http://www.ce.cn/cysc/stwm/gd/202009/ 24/t20200924_35806871.shtml.

[2] H. Liu, Z. Wang, H. Zhen, P. Zhu, X. Wang, and C. Chen, "Effect of recycled coarse aggregate quality on corrosion resistance of concrete," Journal of Civil \& Environmental Engineering, pp. 1-7, 2021.

[3] W. Zhou, Z. Zhang, and Y. Xu, "Mechanics and frost resistance of recycled aggregate inorganic mixture for construction waste," Guide to Materials, vol. 34, no. S1, pp. 234-236, 2020.

[4] M. Kou, X. Liu, S. Tang, and Y. Wang, "3-D X-ray computed tomography on failure characteristics of rock-like materials under coupled hydro-mechanical loading," Theoretical and Applied Fracture Mechanics, vol. 104, no. 7, Article ID 102396, 2019.

[5] R. S. Ravindraraj, M. Steward, and D. Greco, "Variability of recycled concrete aggregate and its effect on concrete properties-a case study in Australia," in Proceedings of the
International Workshop on Recycled Concrete, Tokyo, Japan, September 2000.

[6] Y. T. Wang, X. P. Zhou, and M. M. Kou, “Three-dimensional numerical study on the failure characteristics of intermittent fissures under compressive-shear loads," Acta Geotechnica, vol. 14, no. 4, pp. 1161-1193, 2018.

[7] R. K. Dhir, M. R. Jones, H. E. H. Ahmed, and A. M. G. Seneviratne, "Rapid estimation of chloride diffusion coefficient in concrete," Magazine of Concrete Research, vol. 42, no. 152, pp. 177-185, 1990.

[8] M. M. Kou, Y. J. Lian, and Y. T. Wang, "Numerical investigations on crack propagation and crack branching in brittle solids under dynamic loading using bond-particle model," Engineering Fracture Mechanics, vol. 212, pp. 41-56, 2019.

[9] G. De Schutter, "Quantification of the influence of cracks in concrete structures on carbonation and chloride penetration," Magazine of Concrete Research, vol. 51, no. 6, pp. 427-435, 1999.

[10] K. Kapoor, S. P. Singh, and B. Singh, "Durability of selfcompacting concrete made with recycled concrete aggregates and mineral admixtures," Construction and Building Materials, vol. 128, pp. 67-76, 2016.

[11] R. B. Ramesh, O. Mirza, and W. H. Kang, "Mechanical properties of steel fiber reinforced recycled aggregate concrete," Structural Concrete, vol. 20, no. 2, pp. 745-755, 2019.

[12] S.-N. Aref, B. Javad, A. Sahar, L.-O. Omid, S.-N. Adel, and M. Karimaei, "The effect of recycled concrete aggregates and meta kaolin on the mechanical properties of self-compacting concrete containing nanoparticles," Iranian Journal of Science and Technology, Transactions of Civil Engineering, vol. 43, no. 1, pp. 503-515, 2019.

[13] K Rahal, "Mechanical properties of concrete with recycled coarse aggregate," Building and Environment, vol. 42, no. 1, pp. 407-415, 2007.

[14] C Thomasa, J Setiéna, J.A Polancoa, P Alaejosb, and M Sánchez de Juan, "Durability of recycled aggregate concrete," Construction and Building Materials, vol. 40, pp. 1054-1065, 2013.

[15] P. Zhu, Y. Hao, H. Liu, X. Wang, and L. Gu, "Durability evaluation of recycled aggregate concrete in a complex environment," Journal of Cleaner Production, vol. 273, Article ID 122569, 2020.

[16] B. S. Saini and S. P. Singh, "Flexural fatigue strength prediction of self compacting concrete made with recycled concrete aggregates and blended cements," Construction and Building Materials, vol. 264, Article ID 120233, 2020.

[17] S. P. Singh and S. K. Kaushik, "Fatigue strength of steel fibre reinforced concrete in flexure," Cement and Concrete Composites, vol. 25, no. 7, pp. 779-786, 2003.

[18] D. Cusson, Z. Lounis, and L. Daigle, "Durability monitoring for improved service life predictions of concrete bridge decks in corrosive environments," Computer-Aided Civil and Infrastructure Engineering, vol. 26, pp. 524-541, 2011.

[19] L. Hao, Y. Liu, and J. Xiao, "Durability of recycled aggregate thermal insulation concrete under combined flexural loading and freeze-thaw cycles," Construction and Building Materials, vol. 272, no. 2, Article ID 121652, 2020.

[20] R. Wang, G. Wu, and C. Han, "A study on mix proportion design and mechanical properties of silicon carbide concrete," Road, no. 7, pp. 145-149, 2004.

[21] R. Zhang, "Construction technology of carborundum floor," Industrial Buildings, vol. 43, no. S1, pp. 817-818, 2013.

[22] L. Darren Graham, S. D. Smith, and P. Dunlop, "Lognormal distribution provides an optimum representation of the 
concrete delivery and placement process," Journal of Construction Engineering and Management, vol. 131, no. 2, pp. 230-238, 2005.

[23] D. Graham, S. Smith, and P. Dunlop, "The lognormal distribution provides the optimal representation of the concrete placement process," Journal of Construction Engineering and Management, vol. 131, no. 2, 2005.

[24] B. W. Jo, S. Chakraborty, and H. Kim, "Prediction of the curing time to achieve maturity of the nano cement based concrete using the Weibull distribution model," Construction and Building Materials, vol. 84, pp. 307-314, 2015.

[25] X. X. He and Z. H. Xie, "Experimental study on statistical parameters of concrete strength based on Weibull probability distribution," Key Engineering Materials, vol. 477, pp. 224232, 2011. 